\title{
Technology for Precise Position Control Strategy of PMSM
}

\author{
Yuping Huang ${ }^{1, ~ a}$, Dabin Zhu ${ }^{1, \mathrm{~b}}$, Qingbo $\mathrm{Ma}^{1, \mathrm{c}}$, Hongxing $\mathrm{Wu}^{2, \mathrm{~b}}$ \\ ${ }^{1}$ Beijing Research Institute of Precise Mechatronic Controls, Beijing, 100048, China \\ ${ }^{2}$ Harbin Institute of Technology, Electrical Engineering and Automation, Harbin, 150001, China \\ ashanxi247@163.com, b'zhudabin@sohu.com, cec042991@163.com, whx0422@sina.com
}

\section{Keywords: Current feedback; Permanent-magnet motor; Feed-forward position controller}

\begin{abstract}
Permanent magnet synchronous motor has replaced the dc motor in many occasions and become the mainstream in the servo system. But the dynamic model of the permanent magnet synchronous motor is a strongly coupled variable system. Permanent magnet flux in the machine under different operating conditions are considered constant, accuracy of the model was decreased. In this paper, current deviation of decoupling and current feedback decoupling were compared for the current loop current coupling problem, a more accurate model was established. On the basis of the current inner loop optimization, position feed-forward controller was adopted to optimize the system of position loop.
\end{abstract}

\section{Introduction}

Permanent magnet synchronous motor has the advantages of small size, light weight, high efficiency, high output torque, high power density, etc., it is widely used in industry. Fast driving response, strong anti-interference ability is required in place of some high-performance drive, such as robot, numerical control machine tool system, etc[1]. Therefore, it has important theoretical and practical value to study the high performance drive and servo control system of PMSM.

There are three main control loop of PMSM servo system, position loop, speed loop and current loop, the current loop is the inner loop of the system, the response frequency is required fastest, it is the basic of high performance servo system [2]. Dynamic coupling between D and Q can not be eliminated in permanent magnet synchronous motor model, which creates a lower current control accuracy, the dynamic performance becomes poor [3-4]. For the speed loop, the traditional vector control of the PID regulation is insufficient, more appropriate control strategies are needed to make the system stability and robustness [5]. At present, the servo system is becoming higher, not only higher positioning accuracy, no overshoot, but also quick response are needed in position servo system. It is very difficult to meet the requirements with simple proportional or proportional integral controller [6].

In this paper, current deviation of decoupling and current feedback decoupling were compared for the current loop current coupling problem, a more accurate model was established. On the basis of the current inner loop optimization, position feed-forward controller was adopted to optimize the system of position loop. Simulation results show that the system response speed has been greatly improved, and the following conditions of position signal are improved significantly.

\section{Mathematical Model of PMSM}

For the PMSM, control strategy of $i_{d}=0$ is adopted in the paper, voltage equation of permanent magnet synchronous motor based on synchronous rotating dq coordinate system:

$$
\left\{\begin{array}{l}
u_{d}=R_{s} i_{d}+L_{d} p i_{d}-\omega L_{q} i_{q} \\
u_{q}=R_{s} i_{q}+L_{q} p i_{q}+\omega L_{d} i_{d}+\omega \phi_{f}
\end{array}\right.
$$

where $u_{d}, u_{q}$ is the d-q axis component of the stator voltage; $R_{s}$ is stator resistance; $i_{d}, i_{q}$ are stator current components; $\Psi_{f}$ is rotor flux linkage, $p$ is differential operator.

Equation of flux linkage equation: 


$$
\left\{\begin{array}{l}
\psi_{d}=L_{d} i_{d}+\psi_{f} \\
\psi_{q}=L_{q} i_{q}
\end{array}\right.
$$

where $L_{d}, L_{q}$ is the equivalent inductance of d-q axis; $\Psi_{f}$ is the flux linkage of rotor.

Equation of torque:

$$
T_{e}=\frac{3}{2} P_{n}\left(\psi_{d} i_{q}-\psi_{q} i_{d}\right)
$$

where $P_{n}$ is the number of motor pole.

Fig. 1 shows the structure diagram of PMSM vector control system with $i_{d}=0$. Cascade structure of speed control loop and torque control loop is used in the system, current loop is the inner loop, speed and position loop are outer ring. Comparing the speed command $\omega^{*}$ with the speed response $\omega$, the difference is used as the input of the speed regulator. Comparing the current command $i_{q}$ with the current response $i_{q}{ }^{*}$, the difference is used as the input of the current regulator, the output of the regulator is electromagnetic torque.

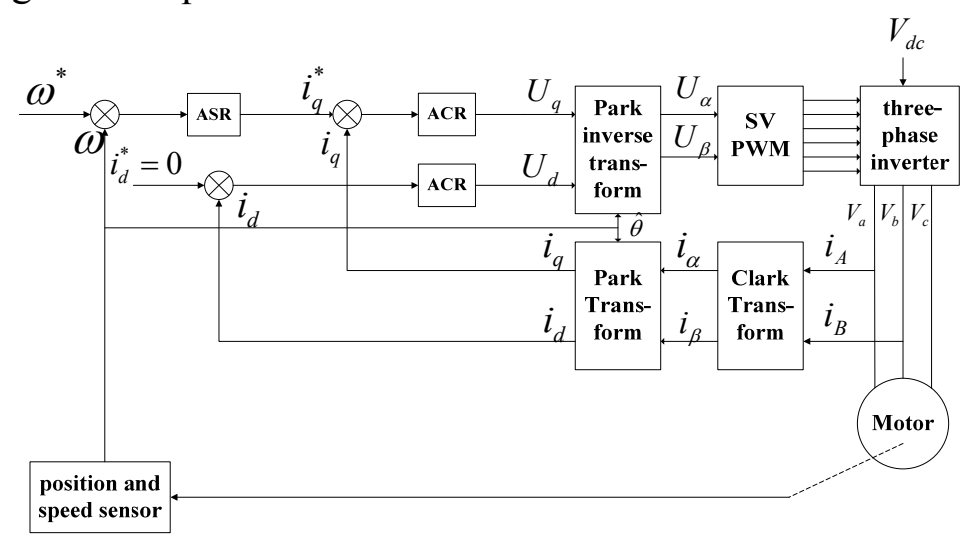

Fig. 1 Block diagram of vector control system for PMSM

\section{Optimization of PMSM system}

The dynamic model of permanent magnet synchronous motor is a high order, nonlinear and strong coupling system, in this chapter, deviation decoupling is used to optimize the model of the motor, feed forward controller is used to optimize the response speed and accuracy of the system.

Current feedback decoupling control of PMSM. Coupling effect of permanent magnet synchronous motor can be compensated by feed forward compensation, coupling term of $\mathrm{d}$ and $\mathrm{q}$ axis voltage equation are introduced at the $d$ and $q$ axis output of current controller, Fig. 2 shows the diagram of current feedback decoupling control.

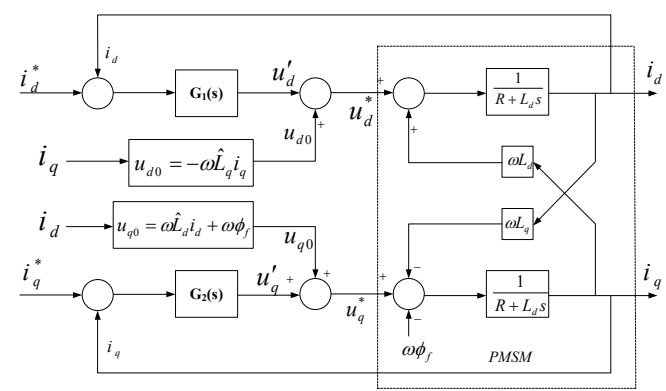

Fig.2 Diagram of current feedback decoupling

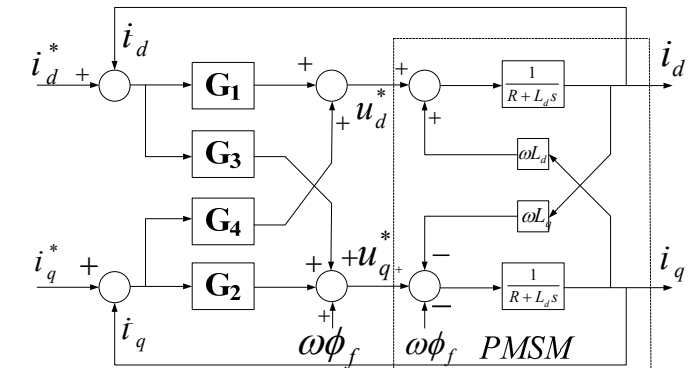

Fig. 3 Diagram of current deviation decoupling

Current deviation decoupling control of PMSM. Current command and current response are calculated to get the coupling voltage in the current deviation decoupling control, and the coupling voltage will be added at the output of the controller. Current deviation decoupling controller can be divided into direct controller (G1, G2) and cross controller(G3, G4), decoupling branch is used to offset the internal coupling effect of permanent magnet synchronous motor, decoupling control of 
motor is realized. Fig. 3 shows the diagram of current deviation decoupling control.

Ignore the anti electromotive force (Assuming that $\omega \phi_{f}$ has been fully compensated), the following equation is derived from Figure 4:

$$
\begin{aligned}
& G_{1}\left(i_{d}^{*}-i_{d}\right)+G_{4}\left(i_{q}^{*}-i_{q}\right)+\omega L_{q} i_{q}=i_{d}\left(R+L_{d} s\right) \\
& G_{2}\left(i_{q}^{*}-i_{q}\right)+G_{4}\left(i_{d}^{*}-i_{d}\right)+\omega L_{d} i_{d}=i_{q}\left(R+L_{d} s\right)
\end{aligned}
$$

According to the decoupling condition: $i_{d}$ only has a relationship with $i_{d}^{*}$, and has nothing to do with $i_{q}^{*} ; i_{q}$ only has a relationship with $i_{q}^{*}$, and has nothing to do with $i_{d}^{*}$. Let

$$
\begin{aligned}
& G_{4}\left(R+L_{q} s\right)+G_{1} \omega L_{q}=0 \\
& G_{3}\left(R+L_{q} s\right)-G_{1} \omega L_{d}=0
\end{aligned}
$$

Therefore $G_{3}=\frac{\omega L_{q}}{R+L_{q} s} G_{1}, G_{4}=-\frac{\omega L_{d}}{R+L_{d} s} G_{1}$

Complete decoupling is implemented according to the type selection of G3, G4. Signal input point has been moved from the front end of the controller to the end of the controller, Fig. 4 shows the diagram of current deviation decoupling control.
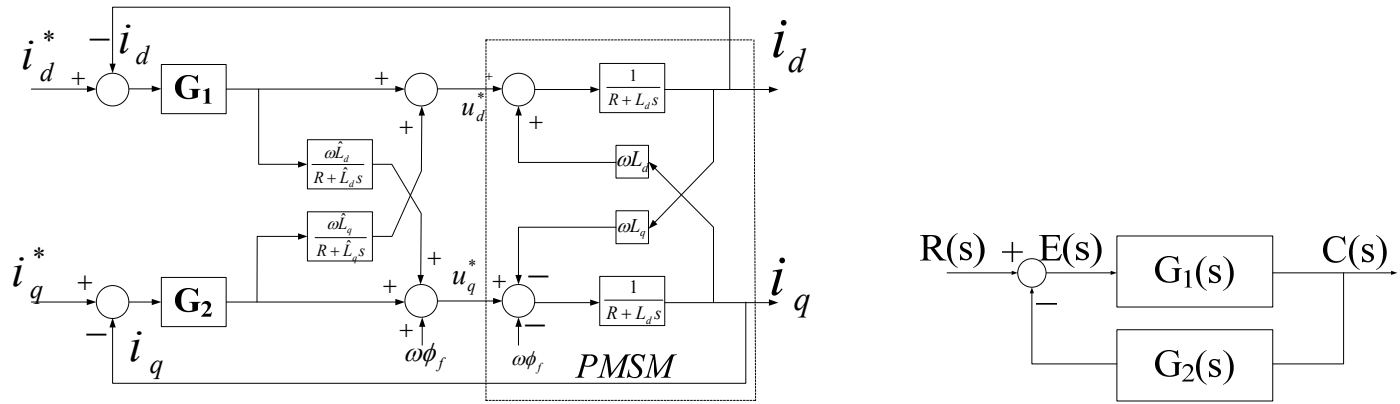

Fig .4 Diagram of current deviation decoupling control Fig. 5 Diagram of servo system control block

Position feed-forward control. For a closed-loop control system, can be simplified into Fig.5, where G1(s) and G2(s) is the forward channel function and feedback function respectively. The output of the system is:

$$
C(s)=E(s) G_{1}(s)
$$

System error is:

$$
E(s)=R(s)-C(s) G_{2}(s)
$$

Therefore,

$$
C(s)=\frac{G_{1}(s)}{1+G_{1}(s) G_{2}(s)} R(s)
$$

The coefficient of $\mathrm{R}(\mathrm{s})$ is the closed-loop transfer function of system, the value of the coefficient is not 1 , feed-forward control increase the feed-forward function to make the closed-loop transfer function value is 1 . The purpose of the feed-forward compensation is to make the input value and output value can be achieved exactly the same, error is compensated before the system error occurred.

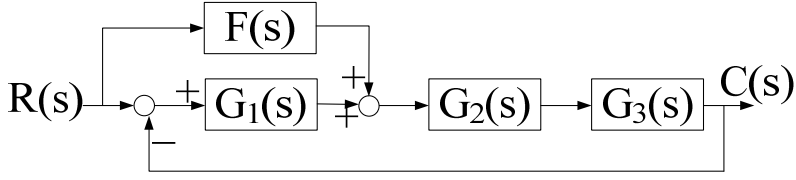

Fig. 6 Diagram of feed-forward compensation system transfer function block

Fig.6 shows the diagram of feed-forward compensation system transfer function block, the 
closed-loop transfer function of system is:

$$
G(s)=\frac{F(s) G_{1}(s) G_{2}(s)+G_{1}(s) G_{2}(s) G_{3}(s)}{1+G_{1}(s) G_{2}(s) G_{3}(s)}
$$

Therefore, the value of the closed-loop transfer function is 1 when $F(s) G_{1}(s) G_{2}(s)=1$. System can realize the output and input no matter whether signal is a slope or acceleration signal:

$$
F(s)=\frac{1}{G_{1}(s) G_{2}(s)}=\frac{T_{v} s^{2}+s}{K_{v}}
$$

Eq. 11 shows that position feed-forward compensation function consists of feed-forward velocity function and feed-forward acceleration function, velocity and acceleration are compensated, the location of the system response improved greatly.

\section{Simulation and Analysis}

This system is composed of position loop, speed loop and current loop, the texting is from inside to outside of system. Simulation experiments based on id $=0$ vector control of Matlab. Motor parameters: rated power $1500 \mathrm{~W}$, rated torque $5 \mathrm{~N} . \mathrm{m}$, rated speed $3000 \mathrm{r} / \mathrm{min}$, rated current $15 \mathrm{~A}$, moment of inertia $9.2 \times 10^{-4} \mathrm{~kg} \cdot \mathrm{m}^{2}$, phase resistance $1.57 \Omega, \mathrm{d} / \mathrm{q}$ phase inductance $3.5 / 8.8 \mathrm{mH}$.

Fig.7 13 show the speed and current response at 3000r/min when the torque changes form 0 to $5 \mathrm{~N} . \mathrm{m}$ at $0.1 \mathrm{~s}$.

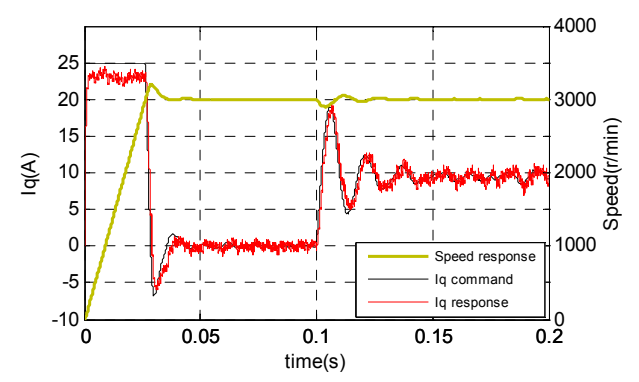

Fig. 7 Iq for the system without decoupling

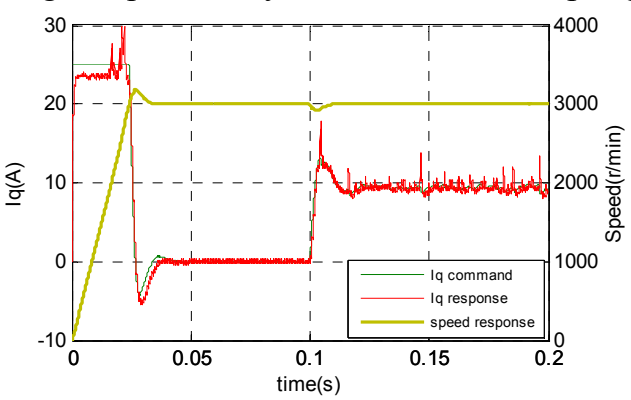

Fig. 9 Iq for current feedback decoupling

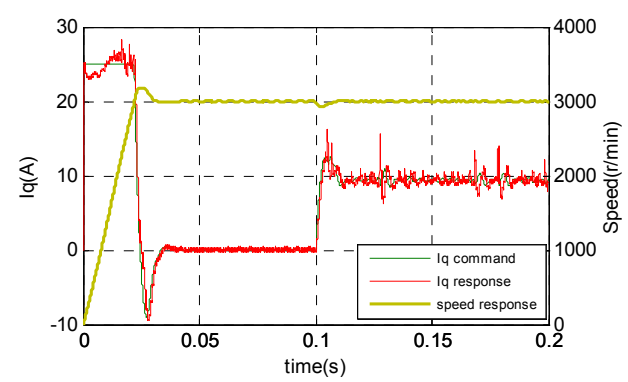

Fig. 11 Iq for current deviation decoupling

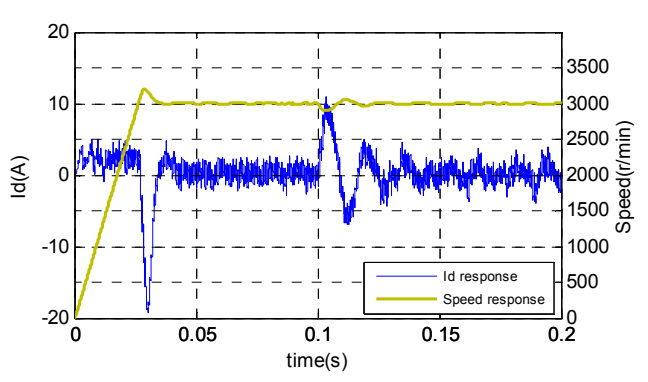

Fig. 8 Id for the system without decoupling

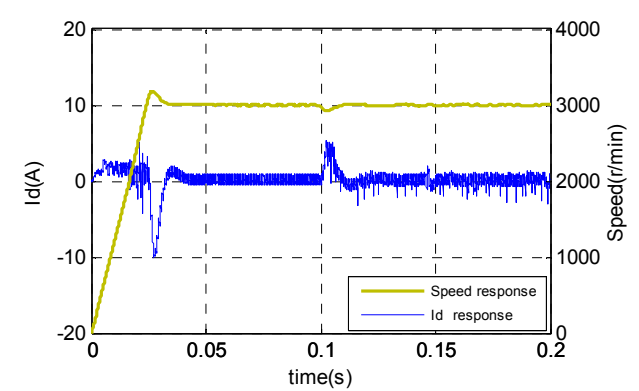

Fig. 10 Id for current feedback decoupling

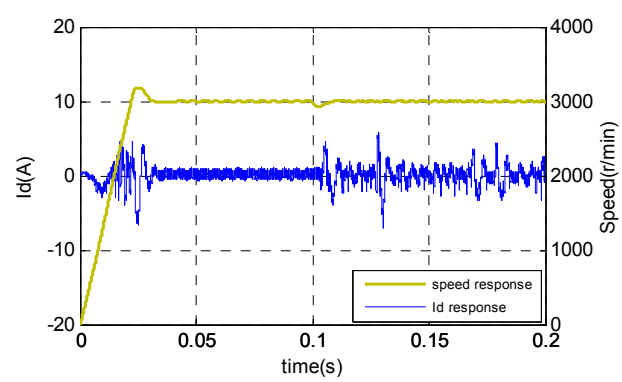

Fig. 12 Id for current deviation decoupling

Fig. 7 shows the $I_{q}$ waveform for the system without decoupling, when the motor starts, $I_{q}$ cannot be good to follow the instructions, and when the torque fluctuations, the maximum current fluctuation is 
about 20A. Fig.9 shows the $I_{q}$ waveform for the system with current feedback decoupling. By comparison, we can see that the following instruction of q axis current has improved. Fig.11 shows the $I_{q}$ waveform for the system with current deviation decoupling, it can be seen by comparing Fig.7, Fig.11 and Fig.9 that the following instruction of q axis current got futher enhanced, only about 15A, the optimization effect is obvious.

Fig.8 shows the Id waveform for the system without decoupling, when the motor starts, there is a big wave in $I_{d}$, the peak is close to 20A. Fig.10 shows the Id waveform for the system with current feedback decoupling, volatility circuit is improved, the peak is about 10A. Fig.12 shows the Id waveform for the system with current deviation decoupling. By comparing the Fig. 8 and Fig. 10 and Fig.12 shows, d-axis current fluctuations have improved significantly after current deviation decoupling, the peak is only about $6 \mathrm{~A}$.

Resistance inductance values are presumed to be constant when most system modeling, but it is not realistic, therefore, the situation of resistance and inductance error exists should be studied. Fig. 13 16 shows the current respectively when parameters estimated error, where $\hat{R}_{s}=0.5 R_{s}$ $\hat{L}_{d}=\hat{L}_{q}=0.5 L_{d}$.

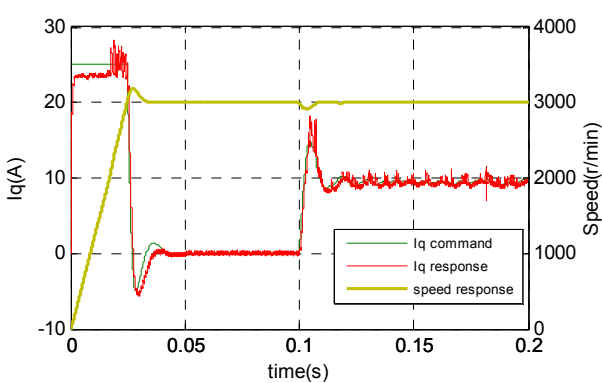

Fig. 13 Current feedback decoupling Iq current

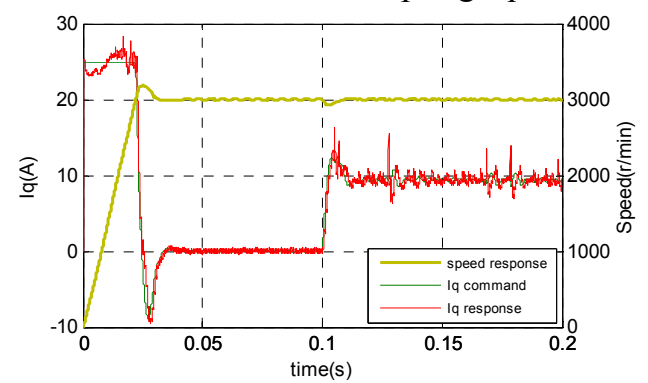

Fig. 15 Current deviation decoupling Iq current

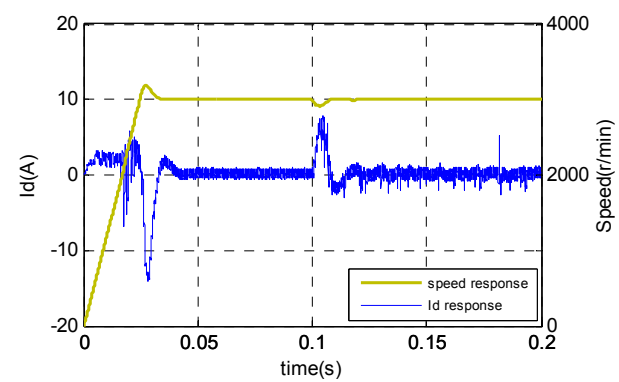

Fig. 14 Current feedback decoupling Id current

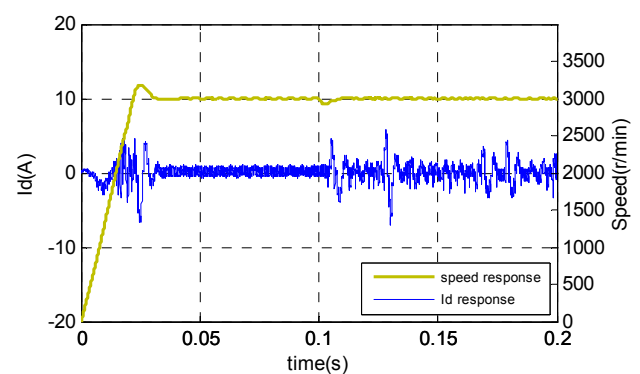

Fig. 16 Current deviation decoupling Id current

By comparing the Fig.13, 14 and Fig.9, 10, when there are error parameters, system optimization effect is obvious poor. By comparing the Fig.15, 16 and Fig.11, 12, when there are error parameters, optimization results do not change in the system, which proves that the current deviation decoupling control has a strong robustness.

The position signal command is a signal of $110^{\circ}, 5 \mathrm{~Hz}$, Fig. 17 and Fig.18 show the following conditions of position signal.
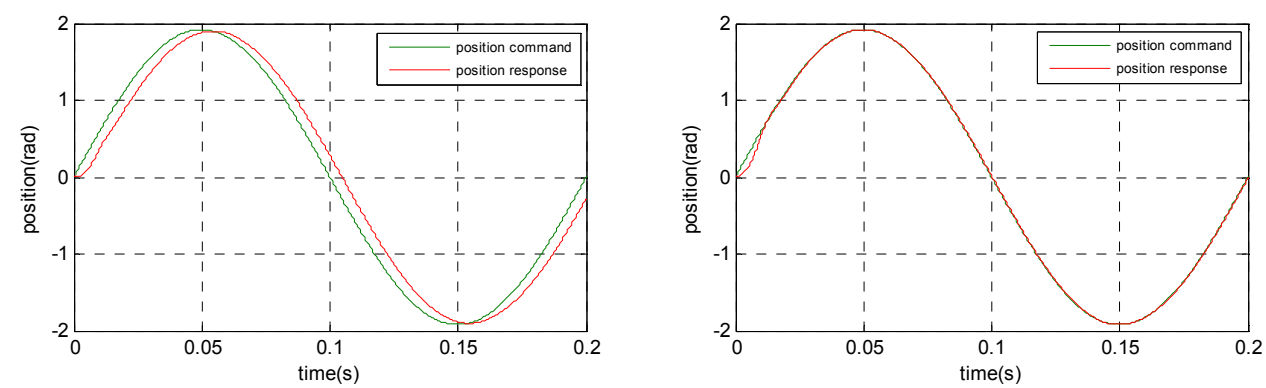

Fig. 17 Position signal with PI controller Fig. 18 Position signal with feed-forward controller

Fig. 17 shows the following conditions of position signal with PI controller, Fig.18 shows the following conditions of position signal with feed-forward controller. When the PI controller is adopted in the system, the position response can not follow the position command well, error always 
exists. But when the feed-forward controller is adopted in the system, the response speed of the system is improved, position signals can be accurately followed in 0.02 seconds, the position input signal is almost the same as the feedback signal, and the optimization effect is very obvious.

\section{Conclusion}

Simulation results show, the control strategy proposed in this paper has achieved good results. The optimization effect mainly has the following points: (1) The following instruction of q axis current got enhanced and d-axis current fluctuations have improved significantly after current deviation decoupling; (2)Compared to the traditional decoupling method, the current deviation decoupling control has a stronger robustness; (3) The position input signal is almost the same as the feedback signal, and the optimization effect is very obvious.

\section{Acknowledgement}

In this paper, the research was sponsored by Natural Science Foundation of China (Project No. 51177025) and China Postdoctoral Science Foundation Funded Project.

\section{References}

[1] Xiaoning Li, The inverse system decoupling control of the permanent magnet synchronous motor in d-q synchronous rotating reference frame, Procedia Engineering, 2011, 24, pp. 78-82.

[2] Tao Yang. Systematic Design of Current Control System for Permanent Magnet Synchronous Motors. International Journal of Control, Automation, and Systems, 2013, 11(6):1128-1136.

[3] Jonq-Chin Hwang. The Current Harmonics Elimination Control Strategy for Six-Leg Three-Phase Permanent Magnet Synchronous Motor Drives[J]. IEEE Transactions on power electronics, 2014, 29(6):3032-3040.

[4] Paolo Mattavelli. Torque-Ripple Reduction in PM Synchronous Motor Drives Using Repetitive Current Control [J]. IEEE TRANSACTIONS ON POWER ELECTRONICS, 2005, 20(6):1423-1431.

[5] Cetin Elmas. A hybrid controller for the speed control of a permanent magnet synchronous motor drive[J]. Control Engineering Practice 16.208:260-270.

[6] Depenbroek M. Direct Self-control(DSC) of Inverter-fed Induction Machine[J]. IEEE Trans on PE, 1988, 3(5):420-429. 